See discussions, stats, and author profiles for this publication at: https://www.researchgate.net/publication/341736668

\title{
Parental bonding: Psychometric properties and association with lifetime depression and anxiety disorders
}

Article in Psychological Assessment · May 2020

DOI: 10.1037/pas0000864

\section{CITATIONS}

5 authors, including:

Marie-Louise Kullberg

Leiden University

5 PUBLICATIONS 1 CITATION

SEE PROFILE

Charlotte van Schie

University of Wollongong

12 PUBLICATIONS 130 CITATIONS

SEE PROFILE

Some of the authors of this publication are also working on these related projects:

Dutch CAPS-5 View project

Project GWAS Meta-Analysis of Cannabis Use View project
READS

5

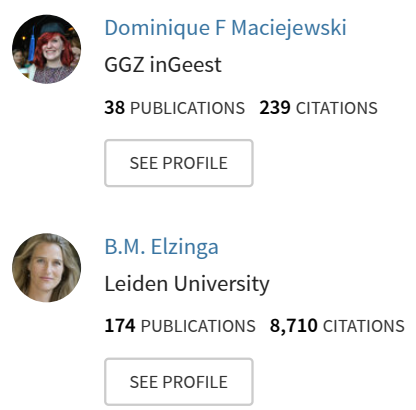




\section{Psychological Assessment}

\section{Parental Bonding: Psychometric Properties and Association With Lifetime Depression and Anxiety Disorders}

Marie-Louise Kullberg, Dominique Maciejewski, Charlotte C. van Schie, Brenda W. J. H. Penninx, and Bernet M. Elzinga

Online First Publication, May 28, 2020. http://dx.doi.org/10.1037/pas0000864

\section{CITATION}

Kullberg, M.-L., Maciejewski, D., van Schie, C. C., Penninx, B. W. J. H., \& Elzinga, B. M. (2020, May 28). Parental Bonding: Psychometric Properties and Association With Lifetime Depression and Anxiety Disorders . Psychological Assessment. Advance online publication.

http://dx.doi.org/10.1037/pas0000864 


\title{
Parental Bonding: Psychometric Properties and Association With Lifetime Depression and Anxiety Disorders
}

\author{
Marie-Louise Kullberg \\ Leiden University \\ Charlotte C. van Schie \\ Leiden University and Leiden University Medical Center
}

\author{
Dominique Maciejewski \\ Radboud University Nijmegen
}

Brenda W. J. H. Penninx

Amsterdam UMC, Free University

\author{
Bernet M. Elzinga \\ Leiden University and Leiden University Medical Center
}

\begin{abstract}
In epidemiology and psychiatry research, the Parental Bonding Instrument (PBI) is commonly used to assess offspring's perception on maternal and paternal behavior during childhood. We tested the 2- versus 3 -factor structure of the 16-item version and assessed measurement invariance across sex and across lifetime depressed, anxious, comorbid affected, and healthy participants. Subsequently, we investigated PBI dimensions across sex and psychopathology groups using structural equation modeling. Participants were 2,069 adults with a lifetime affective disorder and healthy controls, ages 26-75, from the Netherlands. Our findings support the 3-factor solution of the distinct mother and father scales, distinguishing care, overprotection, and autonomy (previously "authoritarianism"). Moreover, measurement of the PBI appeared to be invariant across groups, indicating that means and relations can be reliably compared across sex and psychopathology groups. Men reported more maternal overprotection and paternal lack of care, whereas females reported higher paternal and maternal lack of autonomy and maternal lack of care levels compared with males. Lack of care and lack of autonomy levels were elevated in all affected groups, with the comorbid group showing highest levels of all 3 PBI dimensions. Adults with anxiety disorders reported heightened maternal lack of autonomy levels compared with the depression group and healthy controls. Adults with a depressive disorder reported heightened paternal lack of care levels as compared with the anxiety group and healthy controls. We advocate to use the 3 -factor structure and conclude that suboptimal parental bonding, mainly lack of care and lack of autonomy, is associated with lifetime anxiety and depression.
\end{abstract}

Public Significance Statement

This study supports the 3-factor solution of the Parental Bonding Instrument (PBI) and indicates that means and relations can be reliably compared across sex and psychopathology groups. Especially parental lack of care and lack of autonomy are associated with the presence of lifetime anxiety and depression. Findings highlight negative perceptions of childhood parental bonding play an important role in psychopathology across the entire life span.

Keywords: parental bonding, depression, anxiety, measurement invariance

Supplemental materials: http://dx.doi.org/10.1037/pas0000864.supp

(iD) Marie-Louise Kullberg, Faculty of Social Science, Institute of Psychology, Department of Clinical Psychology, Leiden University; Dominique Maciejewski, Department of Developmental Psychopathology, Behavioral Science Institute, Radboud University Nijmegen; (D) Charlotte C. van Schie, Institute of Clinical Psychology, Leiden University, and Leiden Institute for Brain and Cognition (LIBC), Leiden University Medical Center; Brenda W. J. H. Penninx, Department of Psychiatry, Amsterdam Public Health Research Institute, Amsterdam UMC, Free University; (D) Bernet M. Elzinga, Institute of Clinical Psychology, Leiden University, and Leiden Institute for Brain and Cognition (LIBC), Leiden University Medical Center.

The infrastructure for the NESDA study (www.nesda.nl) is funded through the Geestkracht program of the Netherlands Organisation for Health Research and Development (ZonMw, Grant 10-000-1002) and financial contributions by participating universities and mental health care organizations (VU University Medical Center, GGZ inGeest, Leiden University Medical Center, Leiden University, GGZ Rivierduinen, University Medical Center Groningen, University of Groningen, Lentis, GGZ Friesland, GGZ Drenthe, Rob Giel Onderzoekscentrum). This work was in part supported by the Leiden University Research Profile 'Health, prevention and the human life cycle' as part of the research project 'Family aggregation of mood and anxiety disorders' (Bernet M. Elzinga and Bert van Hemert).

Correspondence concerning this article should be addressed to MarieLouise Kullberg, Faculty of Social Science, Institute of Psychology, Department of Clinical Psychology, Leiden University, P.O. Box 9555, 2300 RB Leiden, the Netherlands. E-mail: m.j.kullberg@ fsw .leidenuniv.nl 
The parent-offspring relation during childhood is of crucial importance for the emotional, psychological, and behavioral development (Bowlby, 1997) throughout the entire life span (Burns, Loh, Byles, \& Kendig, 2018; Kendler, Myers, \& Prescott, 2000). Warmth, care, and protection by parents, that is, key factors contributing to optimal parental bonding, may help establish a solid cognitive framework for constructive social interactions and mental well-being (Bretherton, Ridgeway, \& Cassidy, 1990). In contrast, that is, suboptimal bonding, for instance because of parental rejection, lack of care, warmth, or overprotection, increases the risk of developing difficulties with interpersonal relations and adult psychopathology (Marshall, Shannon, Meenagh, Mc Corry, \& Mulholland, 2018).

Parental warmth and protection as perceived by offspring are often measured with the Parental Bonding Instrument (PBI; Parker, Tupling, \& Brown, 1979). The PBI assesses a respondent's perception of the relation with their mother and their father figure (i.e., biological mother or father, stepmother/stepfather, or other mother/father figure, from here on referred to as "mother" or "father") before the age of 16, originally through two dimensions of parenting, namely Care and Control. The Care Scale assesses the perceived parental warmth, caring, and lovingness, whereas the Control Scale reflects an overprotective and controlling parenting style, sometimes also referred to as "helicopter parenting" (Segrin, Givertz, Swaitkowski, \& Montgomery, 2015). The PBI is widely used in epidemiological studies on mental health (e.g., Enns, Cox, \& Clara, 2002; Xu, Morin, Marsh, Richards, \& Jones, 2018) and recognized as an instrument for affiliation within the Research Domain Criteria (RDoC) framework (National Institute of Mental Health, n.d.). However, there is no consensus yet regarding these dimensions of parenting (i.e., the factor structure of the PBI) and whether these are invariant across different groups (i.e., sex). Thus, the first aim of the study was to examine the factor structure and measurement invariance of the PBI. Moreover, it is unclear how the different types of suboptimal maternal and paternal bonding styles are specifically associated with anxiety disorders versus depression versus comorbid mood disorders. Therefore, the second aim of the study was to elucidate the difference in levels of reported suboptimal parental bonding between lifetime affected patients with depression, anxiety, comorbid mood disorders, and unaffected controls.

\section{Factor Structure of the PBI}

The factor structure of the original version of the PBI has frequently been examined in various samples; however, there is still no consensus. While some studies support the original two factor structure (Kitamura et al., 2009; Parker et al., 1979), other studies point toward a three-factor solution in both a clinical sample from the United Kingdom (Xu et al., 2018) and a nonclinical Japanese sample (Sato et al., 1999). In the three-factor structure, the original Control Scale (Parker et al., 1979) is split up in Overprotection and Authoritarianism Scale (Kendler et al., 1996), whereas items of the Authoritarianism Scale reflect a child's sense of autonomy and independence (e.g., "your mother/father let you decide things for yourself"). In most studies using the three-factor solution, the subscale consisting of the items "My father/mother liked me to make my own decisions," ". . . let me decide things for yourself," ". . . gave me as much freedom as I wanted," and ". . . let me dress in any way I pleased" is referred to as "authoritarianism" (Enns et al., 2002; Heider et al., 2005; Kendler et al., 1996, 2000; Khalid, Qadir, Chan, \& Schwannauer, 2018). Items of the authoritarianism subscale are generally reverse coded to ensure that high values reflect authoritarian parenting. Authoritarian parenting, however, is generally described as a highly directive, domineering, and demanding parenting style, in which parents expect their children to be obedient (Buri, 1991; Yap, Pilkington, Ryan, \& Jorm, 2014), whereas the items of the subscale refer to the extent to which a parent acknowledges a child's opinion, input, and choices and encourages to make own decisions (Kendler et al., 1996; Yap et al., 2014). Therefore, we recommend to use "lack of autonomy-encouraging behavior" or in short "lack of autonomy" instead of "authoritarianism" when referring to this subscale. The Overprotection Scale reflects an overprotective and controlling parenting style including items as for instance "My father/mother did not want me to grow up" and ". . . tried to control everything I did."

Many studies used an abbreviated variant of the PBI, particularly the 16-item version. The shortened inventory also yielded a three-factor structure (Cox, Enns, \& Clara, 2000; Enns et al., 2002; Heider et al., 2006). This version, which is also used in the current sample (Netherlands Study of Depression and Anxiety, NESDA; Penninx et al., 2008), was especially designed for epidemiological studies (Kendler et al., 1996). Research in a clinical sample of female twins (Kendler et al., 2000) and a clinical adolescent sample (Khalid et al., 2018) supports the three-factor structure of the 16-item version; however, this has never been investigated in an adult clinical and nonclinical sample including both males and females.

\section{Maternal and Paternal Bonding: Sex Differences}

The perception of a suboptimal relation with father or mother may affect males and females differently. Males retrospectively reporting lack of paternal care during childhood, retrospectively, are in general at increased risk for mental health problems, whereas this relation was not significant for females (Burns et al., 2018; Xu et al., 2018). Also, the recollections of paternal overprotection seem to be a risk factor for depression in males, but not in females (Heider et al., 2006). Although it is well established that the relationship between perceived parental bonding and psychopathology varies across sex, no clear sex-specific patterns have been identified yet. Moreover, to evaluate the sex differences regarding the link between reported childhood parental bonding and adult psychopathology, we first have to evaluate whether there are sex differences in the reported experiences of the parental bonding. It is expected that the males and females differ in the recollections of the parental bond with father and mother. Against that background, our goal was to test whether the levels of care, overprotection, and lack of autonomy by father and mother differed across sex.

\section{Suboptimal Parental Bonding and Adult Depression and/or Anxiety Disorders}

Many studies have demonstrated that recollections of suboptimal parental bonding during childhood are associated with adult anxiety and depression (Avagianou \& Zafiropoulou, 2008; Bur- 
bach \& Borduin, 1986; Oakley-Browne, Joyce, Wells, Bushnell, \& Hornblow, 1995; Silove, Parker, Hadzi-Pavlovic, Manicavasagar, \& Blaszczynski, 1991; Valiente, Romero, Hervas, \& Espinosa, 2014). The three parental bonding styles, that is, care, overprotection, and lack of autonomy, assessed with the PBI, have different effects on mental health. Reported lack of parental care has been found to have the strongest link with adult depression and anxiety compared with overprotection and lack of autonomy, with stronger associations with lack of care by mothers compared with fathers (Enns et al., 2002; Kendler et al., 2000). Lack of parental sensitivity and adequate care can contribute to low self-esteem, negative beliefs about oneself, such as the idea of not being good enough or feelings of worthlessness, and maladaptive coping (Bartholomew \& Horowitz, 1991; Meites, Ingram, \& Siegle, 2012). These cognitive vulnerabilities can in turn increase the risk of mood disorders in the long-term (Finzi-Dottan \& Karu, 2006; Wei, Heppner, \& Russell, 2006).

Next to parental care, perceived overprotective parenting is also linked to both depression and anxiety in adulthood (Overbeek, ten Have, Vollebergh, \& de Graaf, 2007). However, the different influences of fathers versus mothers remains equivocal. For instance, in a study in six European countries, high levels of reported overprotection by mother, but not by father, was linked to lifetime mood disorders (Heider, Matschinger, Bernert, Alonso, \& Angermeyer, 2006). Furthermore, perceived maternal overprotection has been associated with lifetime social phobias, specific phobias, and depression, whereas paternal overprotection was only associated to agoraphobia in males, and not to other affective disorders (Enns et al., 2002). Recollections of childhood maternal overprotection were associated with physical symptoms of anxiety and fear of dying, whereas paternal overprotection was linked to a decreased self-esteem and dysfunctional self-beliefs (Meites et al., 2012). These findings highlight the distinct role of maternal and paternal overprotection in the association with anxiety and depression.

Contrary to findings linking perceived lack of childhood parental care or overprotection and adult anxiety and depression, literature on the adverse effects of parental lack of autonomy is less conclusive. Whereas perceived lack of autonomy is linked to both anxiety and depression in some studies (Yap et al., 2014), in others it was not found to be associated with the occurrence of depression (Heider et al., 2006; Khalid et al., 2018) nor anxiety, such as social phobia and agoraphobia (Enns et al., 2002; Lieb, Isensee, Höfler, Pfister, \& Wittchen, 2002). Moreover, even when studies found indications that lack of autonomy is related to increased psychopathology risk, the effect sizes are usually smaller compared with care (Kendler et al., 2000; Valiente et al., 2014). Retrospectively, reporting a lack of independency as a child as a result of overprotective or authoritarian parenting, however, has also been associated with more externalizing psychopathology, such as drug abuse (Kendler et al., 2000) and antisocial personality (Enns et al., 2002).

Parental bonding styles in persons with comorbid depression and anxiety has to the best of our knowledge not been investigated, nor been compared with persons affected by solely lifetime depression or anxiety. Thus, we aimed to study the levels of perceived lack of care, overprotection and lack of autonomy across four psychopathology groups: lifetime depressed, anxious or comorbid affected (anxiety and depression), and unaffected participants. Patients with the comorbid diagnoses are known to be extra vulnerable. For instance, they report higher levels of childhood trauma, neuroticism, an earlier age of onset and a higher percentage of family history of anxiety, and depression compared with patients with only depression or anxiety (Lamers et al., 2011). Therefore, it is expected that this patient group shows the highest levels of all three suboptimal bonding styles, followed by the groups with lifetime depression or anxiety. Considering abovementioned findings, it is hypothesized that a lack of parental care is elevated in the comorbid and depression groups and we expect higher levels of overprotection in the comorbid and anxiety groups compared with healthy controls. It is also expected that the levels of lack of autonomy are elevated in the affected groups compared with healthy controls, but do not differ between depression and anxiety.

\section{Measurement Invariance}

Several studies found differences in perceived parental bonding between males and females (Enns et al., 2002; Mackinnon, Henderson, Scott, \& Duncan-Jones, 1989), and across psychopathology, particularly depression and anxiety disorders, but also such as personality disorders (Enns et al., 2002; Nordahl \& Stiles, 1997). However, one prerequisite to draw valid conclusions about mean differences in constructs, is that the measurement is equal across groups (e.g., sex, psychopathology). For instance, if males and females have different starting values, factor loadings, and residual variances on a certain questionnaire, then conclusions about sex differences can be biased, because the underlying construct is measured differently for males than for females. Testing whether the construct is measured similarly between groups can be established by testing measurement invariance (Chen, Sousa, \& West, 2005; Vandenberg \& Lance, 2000). Measurement invariance involves testing of hierarchical models of different measurement invariance forms. The theoretical assumption comes from classical test theory, where the response to an item is a linear function of an item intercept (i.e., starting value), regression slope (i.e., factor loading), and measurement error (i.e., residual variance). To determine whether the measurement is equal across groups, each of the components is hierarchically constrained to be equal across groups (Maciejewski, van Lier, Branje, Meeus, \& Koot, 2017; Vandenberg \& Lance, 2000). If the measurement of a construct does not differ across groups (i.e., is invariant), this does not mean that the construct itself cannot differ across groups. In this case, the observed differences are not because of differences in measurement, but because of true differences. Whereas studies have shown that the original version of the PBI is invariant across age groups (Tsaousis, Mascha, \& Giovazolias, 2012) and across sex (Xu et al., 2018), it is unclear whether the abbreviated 16-item version is invariant across sex and across psychopathology groups (lifetime depression vs. lifetime anxiety vs. lifetime comorbid depression/ anxiety vs. healthy controls).

\section{Current Study}

Based on findings from earlier studies on the 16-item version of the PBI, our overall research objective is threefold: The first aim of the current study is to evaluate the factor structure of the PBI by testing the model fit of the two versus three-factor structure. The second aim is to test the measurement (in)variance of the PBI across sex and the four psychopathology groups, to examine 
whether the measurement of the PBI is equivalent for males and females and individuals with anxiety, depressive or comorbid disorders, or no lifetime mood/anxiety disorder. Third, we aim to test differences in levels of suboptimal parental bonding styles across sex and across lifetime depressed, anxious, comorbid affected (anxiety and depression), and healthy participants.

\section{Method}

\section{Procedure}

The NESDA study is an ongoing longitudinal cohort study designed to examine the onset, course, and consequences of depressive and anxiety disorders. At baseline a sample of 2,981 individuals aged 18-65 years was included, consisting of persons with a history of depression and/or anxiety disorders, persons with a current depression and/or anxiety disorder, and healthy controls. Respondents were recruited in the general population and in specialized health care services. General exclusion criteria were a primary diagnosis of severe psychiatric disorders such as psychotic, obsessive-compulsive, bipolar, or severe addiction disorder, and not being fluent in Dutch. A detailed description of the NESDA design and sampling procedures can be found elsewhere (Penninx et al., 2008). The research protocol was approved by the Ethical Committees of the participating universities and all respondents provided written informed consent.

\section{Sample}

In the current study we included participants $(N=2,069)$ from the 9-year follow-up assessment (data collection time point six (T6); 2014-2017), the wave during which the PBI was administered. PBI score was available of 1,915 participants for reports about the mother and 1,826 for reports about the father. In the final sample, $66.1 \%$ was female, the age at T6 ranged from $26-75$ years $(M=50.84, S D=13.11)$, and years of education ranged from 5-18 years $(M 13.00, S D=3.33)$. The presence of a disorder was thoroughly assessed across 9 years and diagnosed using the Composite Interview Diagnostic Instrument (CIDI, Version 2.1; World Health Organization, see below). A lifetime diagnosis is defined as one or more episodes of a depressive or anxiety disorder in the past. Of the total sample at T6 $(N=2,069), 15.9 \%(n=329)$ had a lifetime depressive disorder (MDD or dysthymia), 9.6\% $(n=$ 199) had an anxiety disorder (panic disorder with or without agoraphobia, social anxiety disorder, generalized anxiety disorder, or agoraphobia without panic disorder), 55.4\% $(n=1,146)$ had comorbid anxiety and depression and $19.1 \%(n=396)$ had no lifetime affective disorder (healthy). In the month before assessment, $15.7 \%(n=325)$ of the participants reported an episode of anxiety and $11.3 \%(n=234)$ of depression.

\section{Measures}

Parental bonding-PBI. Parent-child relationship was measured with the shortened 16-item PBI based on Parker et al.'s (1979) original 25-item instrument. Respondents were asked to report on their experiences with their mother and father separately, when they were growing up (before the age of 16). The instrument is a self-report measure and responses are scored on a 4-point
Likert scale (ranging from $1=$ a lot to $4=$ not at all). The 16 item PBI used in this study was especially developed for epidemiological research (Kendler et al., 1996, eliminating the original Items 2, $3,6,10,14,20,22$, and 24). The two-factor solution consists of the Care (Items 1, 2, 3, 7, 8, 11, and 12), and Control (Items 4, 5, 6, $9,10,13,14,15$, and 16) subscales, and in the three-factor solution the Control Scale is further divided in Lack of autonomy (Items 4, 10, 14, and 16) and Overprotection (Items 5, 6, 9, 13, and 15). The items of the Care-subscale assess warmth, caring and lovingness of the parent-child relationship (e.g., My father/mother spoke to me with a warm and friendly voice). The items of the Overprotection Scale reflect an overprotective and controlling parenting style (e.g., My father/mother did not want me to grow up), and the items of the Autonomy Scale assess a parental style that reflects a child's sense of autonomy and independence (e.g., My father/mother let me decide things for myself). The items of the Control Scale and two items (2 and 12) of the Care Scale were reverse coded to make sure that high scores reflect suboptimal parental bonding, that is, lack of care, lack of autonomy-encouraging behavior or overprotective parenting (see online supplemental materials). In the current sample the internal consistency appeared to be good to excellent for the PBI total score on mother and father (total maternal bonding: $\alpha=.88$; total paternal bonding: $\alpha=.88$ ), for the subscales of the two-factor solution (maternal Lack of Care: $\alpha=$ .89 , paternal Lack of Care: $\alpha=.90$, maternal Control: $\alpha=.82$, paternal Control: $\alpha=.80$ ) and also for the subscales of the three-factor solution (paternal Lack of Autonomy: $\alpha=.85$, maternal Lack of Autonomy: $\alpha=.84$, paternal Overprotection: $\alpha=$ .70, maternal Overprotection: $\alpha=.73$ ).

\section{Psychopathology.}

Composite Interview Diagnostic Instrument (CIDI). The presence (current and lifetime) of Diagnostic and Statistical Manual for Mental Disorders-Fourth Edition-Text Revised (DSM-IVTR; American Psychiatric Association, 2000) depressive (dysthymia and major depressive disorder) and anxiety (generalized anxiety disorder, social phobia, panic disorder with or without agoraphobia, and agoraphobia) disorders was established using Composite Interview Diagnostic Instrument (CIDI, Version 2.1, WHO). The CIDI is used worldwide in clinical and epidemiological studies (e.g., de Graaf et al., 2010; Kessler et al., 2010) and high validity for depressive and anxiety disorders (Wittchen, 1994) was found.

Inventory of Depressive Symptoms (IDS). Depressive symptoms, as assessed with the Inventory of Depressive Symptomatology, were included in the analysis on sex differences to control for current mood. The IDS is a self-report questionnaire designed to assess the severity of depressive symptoms (Rush, Giles, \& Schlesser, 1986; Rush, Gullion, Basco, Jarrett, \& Trivedi, 1996). The IDS assesses all $D S M-I V$ criterion symptom domains for major depressive disorder, commonly associated symptoms (e.g., anxiety, irritability), and symptoms relevant to melancholic and atypical features. The questionnaire consists of 30 items, each with four answering options from 0 through 3 . Sum scores on the items range from 0 to 84 , with higher values indicating more severe symptoms of depression. The psychometric properties of the IDS-SR have shown to be acceptable; for instance, high correlations were found between the IDS and scores on the Hamilton Depression Rating Scale and Beck depression Inventory (Rush et al., 1996). The IDS showed excellent internal consistency $(\alpha=$ 
.98 ) in the current sample. Information on the IDS was available for 1,950 participants.

Beck's Anxiety Inventory (BAI). The Beck Anxiety Inventory (BAI) is a 21-item self-report instrument that assesses the overall severity of anxiety (Beck, Epstein, Brown, \& Steer, 1988). The BAI scores were used to control for current levels of anxiety in the analyses comparing males and females. The respondents are asked to rate how much he or she has been bothered by each symptom over the past week on a 4-point scale, ranging from 0 (not at all) to 3 (severely, I could barely stand it). The BAI is scored by summing the ratings for all of the 21 symptoms to obtain a sum score that can range from 0 to 63 , which are used in this study. The total BAI scale obtained high internal consistency in the current sample $(\alpha=.98)$. Moreover, a good validity and reliability were found (Beck et al., 1988). Sum scores of the BAI were available for 1945 participants.

\section{Missing Data}

Of all participants, 154 did not complete the PBI about mother and 243 did not complete the PBI about father. For some of the participants the reason was that they did not have a father-figure ( $n=73)$, or mother-figure $(n=6)$ or neither of them $(n=4)$. Participants who did not complete the PBI-mother were slightly younger, $t(2,067)=-2.68, p=.007$ and less educated than completers, $t(2,067)=-2.38, p=.018$. Age and education were taken into account in the analyses. Participants who did not complete the PBI-father did not differ on sex, age, and years of education compared with completers (all $p$ values $>.05$ ). The pattern of missing data for PBI resembled a missing-at-random (MAR) pattern $\left(\chi^{2}=1569.42, d f=1208, \chi^{2} / d f\right.$ ratio $\left.=1.29\right)$. Therefore, in the analyses, full Maximum Likelihood Estimation (FIML) was used to control for missing data (Arbuckle, 1996).

\section{Statistical Analyses}

Data preparation was performed with SPSS Statistics 25.0 (IBM Corp., 2017). All other analyses were done in R Version 3.5.1 (R Core Team, 2018) with the lavaan-package Version 0.6-3 (Rosseel, 2012). Models were estimated using the maximum likelihood (ML) estimator. In all analyses, we fitted models using Confirmatory Factor Analysis (CFA). For model identification purposes, the first item's factor loading was fixed to 1 to set the scale of each factor and the first item's intercept was fixed to 0 to set the mean of each factor (Vandenberg \& Lance, 2000). Moreover, we allowed for correlations between higher order factors. The $\mathrm{R}$ code and all model output are available online (https://osf.io/kz2s7/) to reproduce all analyses.

Research Question 1: Two versus three-factor structure of the PBI. To answer our first research question, we fitted two models using CFA: A two-factor structure model (Care, Control) and a three-factor structure model (Care, Overprotection, Autonomy) for maternal and paternal bonding separately. To test whether the two or three factors fit the data best we compared these two solutions using model fit indices. Model fit was evaluated using the Tucker-Lewis Index (TLI), the comparative fit index (CFI), the root mean square error of approximation (RMSEA) and standardized root mean square residual (SRMR). For the TLI and CFI, values between .90 and .95 are considered acceptable, and values of .95 and greater as good. For the RMSEA and SRMR, acceptable models have values of .10 or less (Chen, 2007; Cheung \& Rensvold, 2002).

Research Question 2: Measurement invariance across sex and psychopathology groups. Measurement invariance of the PBI (i.e., configural, metric, scalar, and strict) across sex and across psychopathology groups (lifetime depression, lifetime anxiety, lifetime comorbid anxiety, and depression and healthy participants) was examined to test whether the measurement was the same across groups. In the configural model, the factor structure is the same across groups but no parameters are set to be equal to one another across groups. If configural variance is established, this indicates that the factor structure is similar between groups (i.e., that the same items load on the same overall factor). In the metric model, all factor loadings are constrained to be the same across groups. If metric invariance is established, this indicates that the items contribute in the same way to the overall factor between groups, making it possible to compare relations between groups. Scalar invariance is important to be able to compare groups in mean levels; to this end, the intercepts are constrained to be equal across groups, indicating that individuals have common starting points in rating items. Last, the residual variances were constrained to be the same across groups to test strict invariance that would implicate that the amount of error is similar between groups (Chen et al., 2005; Gregorich, 2006). In practice, strict invariance is often not established, but is not necessary to conduct tests of differences in relations and means. Differences in fitting between the nested models was evaluated using $\triangle \mathrm{CFI}$. A change in CFI smaller than .01 is an indication of measurement invariance (Cheung \& Rensvold, 2002), which is known as a reliable criterion for measurement invariance model comparisons (Chen, 2007; Cheung \& Rensvold, 2002). The chi-square difference test was not used, because it is overly sensitive to trivial deviations in large samples (Marsh, Hau, \& Grayson, 2005; Putnick \& Bornstein, 2016). Additional analyses to test whether father and mother items can be combined into aggregated scales were conducted (Table S2 in the online supplemental materials). Results showed that a scalar invariance model constraining factor loadings and intercepts to be equal across father and mother items resulted in a worse fitting model compared with the metric model, allowing intercepts to be freely estimated across father and mother items (Table S3 in the online supplemental materials). These findings indicate that starting values differed across items for father and mother and, therefore, it is not recommended to combine these items into one aggregated scale.

Research Question 3: Suboptimal parental bonding styles across sex and across lifetime (comorbid) anxiety and depression. To evaluate differences between maternal and paternal bonding (i.e., of Care, Overprotection, and Autonomy) between males and females (research Question 3a) and between lifetime depressed, anxious, comorbid affected, and healthy participants (research Question 3b) we fitted the CFA models for all groups. We compared two nested models, one in which latent means were estimated freely between groups and one in which latent means were constrained to be equal across groups. If model fit significantly worsens, this is an indication that means differ between groups. In case of significant overall differences (omnibus test), post hoc tests were performed to identify which groups differed on which subscales. We ran these nested multiple group 
models for males and females (3a) and for the four psychopathology groups (3b) separately. To control for confounding variables, participant's age and years of education were included in the models testing sex and psychopathology differences. Current levels of depression (as measured with the IDS) and anxiety (as measured with the BAI) were added in the models testing sex differences. In the models testing differences between psychopathology, sex was additionally added as a covariate. The influence of covariates was constrained to be equal across groups, because otherwise the interpretation of the parameters is not equal across different values of the covariates (comparable with the homogeneity of slope assumption in an analysis of covariance [ANCOVA]). Chisquare difference tests were used to compare the models. In view of the large number of comparisons, significance levels were corrected using the Benjamini-Hochberg procedure (Benjamini \& Hochberg, $1995)$ for multiple testing with a false discovery rate of $5 \%$. In tables, raw $p$ values are represented.

\section{Results}

\section{Two Versus Three Factor Structure}

The two and three factor models were tested for maternal and paternal bonding separately. The two-factor structure ("Care" and "Control") showed a relatively poor fit to the data for both maternal and paternal bonding, see Table 1 . In contrast, the three-factor structure (Care, Overprotection, and Autonomy) showed an acceptable model fit. Factor loadings for the three-factor solution ranged from .60 to .89 for Care and .68 to .88 for Autonomy. Factor loadings for Overprotection were somewhat lower, ranging from .50 to .72 (all significant at $p<.001$; Figure 1 ).

\section{Descriptive Statistics}

Sample means, standard deviations, and correlations of all study variables can be found in Table 2. In the current sample levels of depressive symptoms, measured with the Inventory of Depressive Symptomatology (IDS), ranged from $0-69(M=14.85, S D=$ $11.67)$ and levels of anxiety symptoms, measured with the Beck Anxiety Inventory (BAI), ranged from $0-63(M=7.67, S D=$ 8.36). As shown in Table 2, maternal and paternal bonding were highly correlated, $r=.560, p<.01$. Moreover, all PBI subscales and total scores for paternal and maternal bonding were positively correlated with anxiety and depressive symptoms (all $r \mathrm{~s}>.146$ ). In Table 3, the comparison between comorbid (anxiety and depression), depressed, anxious, and healthy persons is represented. The comorbid affected group had less years of education and higher levels of depressive and anxiety symptoms. Moreover, proportionally, this group contained more persons with a current anxiety or depression diagnosis compared with the other groups.

\section{Measurement Invariance Across Sex and Psychopathology Groups}

Next, we estimated the configural invariance of the three-factor model of the PBI simultaneously in both males and females by fitting a multiple group model. Statistics on model fit and comparisons can be found in Table 4. This configural model, allowing parameters to be freely estimated across groups, had an acceptable fit. A metric invariance model constraining factor loading to be equal across groups did not result in a worse fitting model, indicating metric invariance. Similarly, a subsequent scalar invariance model constraining factor loadings and intercepts to be equal across groups did not result in a worse fitting model, indicating scalar invariance. Lastly, the strict invariance model constraining residual variances to be equal across males and females also yielded a good-fitting model did also not result in a worse fitting model, indicating that strict invariance across sex was established for both maternal and paternal bonding. We further analyzed the measurement invariance of the three-factor model across the four psychopathology groups; healthy $(n=396)$, lifetime depressed $(n=329)$, lifetime anxious $(n=119)$, and the lifetime comorbid group ( $n=1,146)$, see Table 4 . The three-factor model of the PBI (maternal and paternal bonding) was invariant across psychopathology groups (up to scalar, but not strict invariance). Together, these results indicate that the PBI is measurement invariant across sex and psychopathology groups, indicating that the measurement is equal across these groups and relations as well as means can be reliably compared.

\section{Latent Mean Differences Between Males and Females and Psychopathology Groups}

To answer our third research question whether males and females differ in their levels of parental bonding, we compared the

Table 1

Two Versus Three Factor Structure

\begin{tabular}{|c|c|c|c|c|c|c|}
\hline Model & $x^{2}$ & $d f$ & CFI & TLI & RMSEA & SRMR \\
\hline $\begin{array}{l}\text { Model } 1 \text { - Maternal bonding } \\
\text { Two factor model: Care and control }\end{array}$ & 90.2 & 103 & 860 & 0.837 & 0.097 & 0.073 \\
\hline $\begin{array}{l}\text { Model } 2 \text { - Maternal bonding } \\
\text { Three factor model: Care, overprotection, and autonomy }\end{array}$ & 1011.6 & 101 & 0.932 & 0.920 & 0.068 & 0.051 \\
\hline $\begin{array}{l}\text { Model } 1 \text { - Paternal bonding } \\
\text { Two factor model: Care and control }\end{array}$ & 1883.3 & 103 & 0.871 & 0.850 & 0.096 & 0.073 \\
\hline $\begin{array}{l}\text { Model } 2 \text { - Paternal bonding } \\
\text { Three factor model: Care, overprotection, and autonomy }\end{array}$ & 940.8 & 101 & 0.939 & 0.928 & 0.067 & 0.048 \\
\hline
\end{tabular}

Note. $\mathrm{CFI}=$ comparative fit index; RMSEA $=$ root mean square error of approximation; TLI $=$ Tucker-Lewis index; SRMR = standardized root mean square residual. Given our large sample, and as $\chi^{2}$ is sensitive to sample size, we only used $\chi^{2}$ for descriptive purposes (Kline, 2010). 

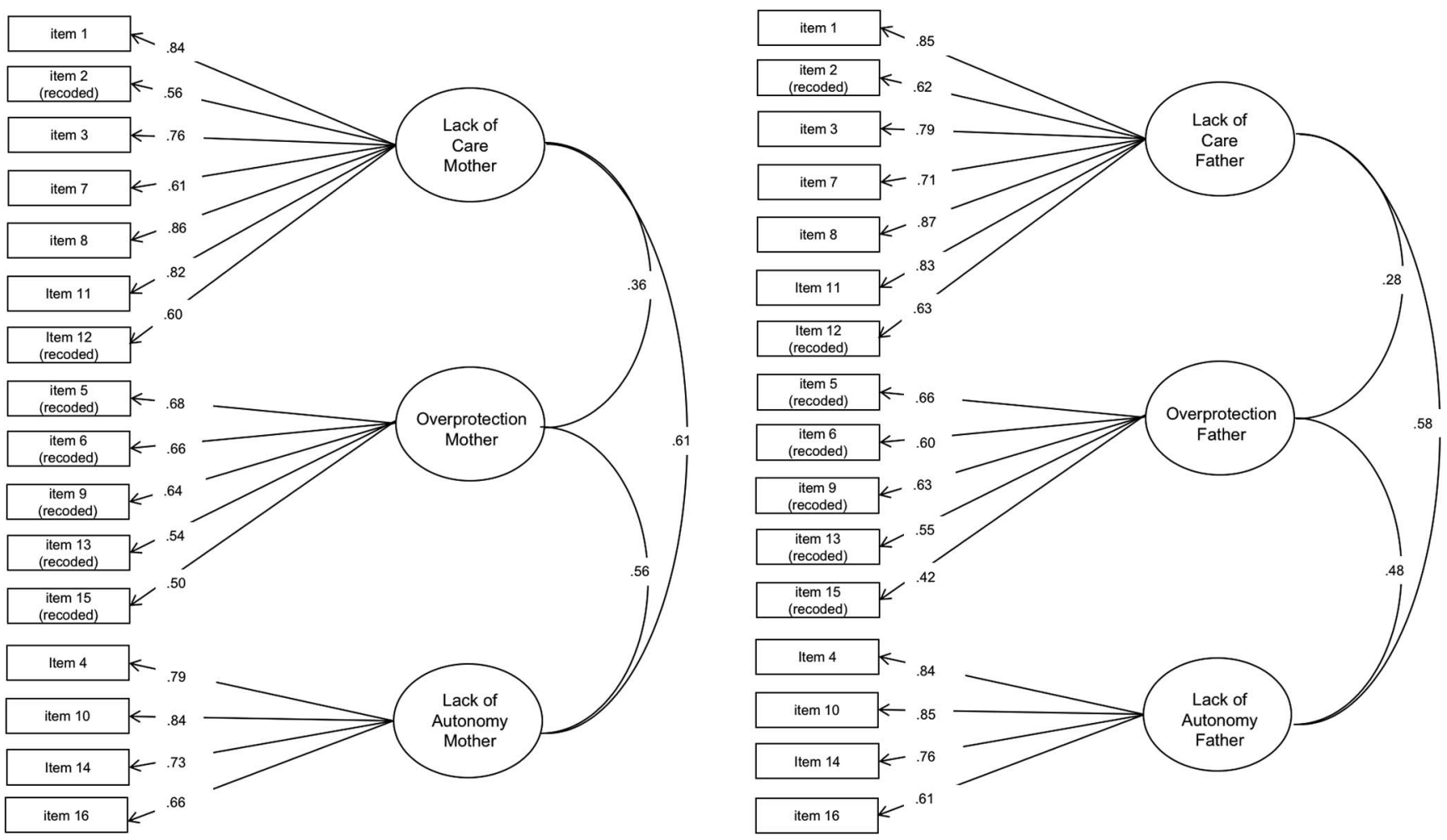

Figure 1. Three factor models of the Parental Bonding Instrument (PBI; left: maternal bonding, right: paternal bonding) with item loadings on the latent factors. Reported factor loadings are standardized and all statistically significant $(p<.001)$.

base model, which contained freely estimated latent means, with a model where the latent means of the PBI subscales constrained to be equal across sexes. The chi-square difference test showed that the levels of Care, Overprotection, and Autonomy differed between males and females for both the mother $\left(\Delta \chi^{2}(\Delta d f)=\right.$ 25.01(3), $p<.001)$ and the father figure $\left(\Delta \chi^{2}(\Delta d f)=36.41(3)\right.$, $p<.001)$. Chi-square tests showed that females reported more lack of care from mother and more lack of autonomy from both parents compared with males (see Table 5). Males reported more paternal lack of care and maternal overprotection compared with females. Groups did not differ in their reported levels of paternal overprotection.

Next, we tested whether levels of paternal and maternal bonding differed across participants with lifetime depression, anxiety, comorbid depression, and anxiety and healthy controls. For this, we constrained the latent means of the PBI subscales to be equal between the four participant groups. The chi-square difference tests were significant for maternal bonding $\left(\Delta \chi^{2}(\Delta d f)=\right.$ $219.75(9), p<.001)$ and paternal bonding $\left(\Delta \chi^{2}(\Delta d f)=194.37(9)\right.$, $p<.001)$, indicating differences between the groups in levels of Care, Overprotection, and Autonomy (see Table 6). Post hoc tests showed that of all lifetime affected groups, the comorbid group reported overall the highest levels of lack of Care, Overprotection, and lack of Autonomy compared with the groups with depression or anxiety only. Compared with healthy controls, the depression group showed higher levels of maternal and paternal lack of care, paternal overprotection, maternal and paternal lack of autonomy, but not maternal overprotection. Also, the depression group showed higher levels of paternal lack of care when comparing to the anxiety group. The anxiety group, however, showed higher levels of maternal lack of autonomy when comparing with the depression group. Moreover, the anxiety group reported higher levels of maternal lack of care, maternal and paternal lack of autonomy, but not maternal or paternal overprotection nor paternal lack of care, when comparing to unaffected healthy persons. Figure 2 illustrates the differences between groups on all PBI subscales separately for father and mother (all $\chi^{2}$ difference tests and $p$ values of the post hoc tests can be found in the online supplemental materials).

\section{Discussion}

The present study examined the factor structure and measurement invariance of the PBI between males and females and among different psychopathology groups (anxiety, depression, comorbid, and no lifetime diagnosis) in a large sample of people with anxiety and depression disorders and healthy controls. Moreover, we tested differences between males and females and psychopathology groups of the PBI subscales. A three-order factor structure fitted the data best and scalar measurement invariance across sex and psychopathology groups was found. Moreover, levels of care, overprotection, and autonomy differed across sex and psychopathology group. Results and their implications are discussed below. 
KULLBERG ET AL.

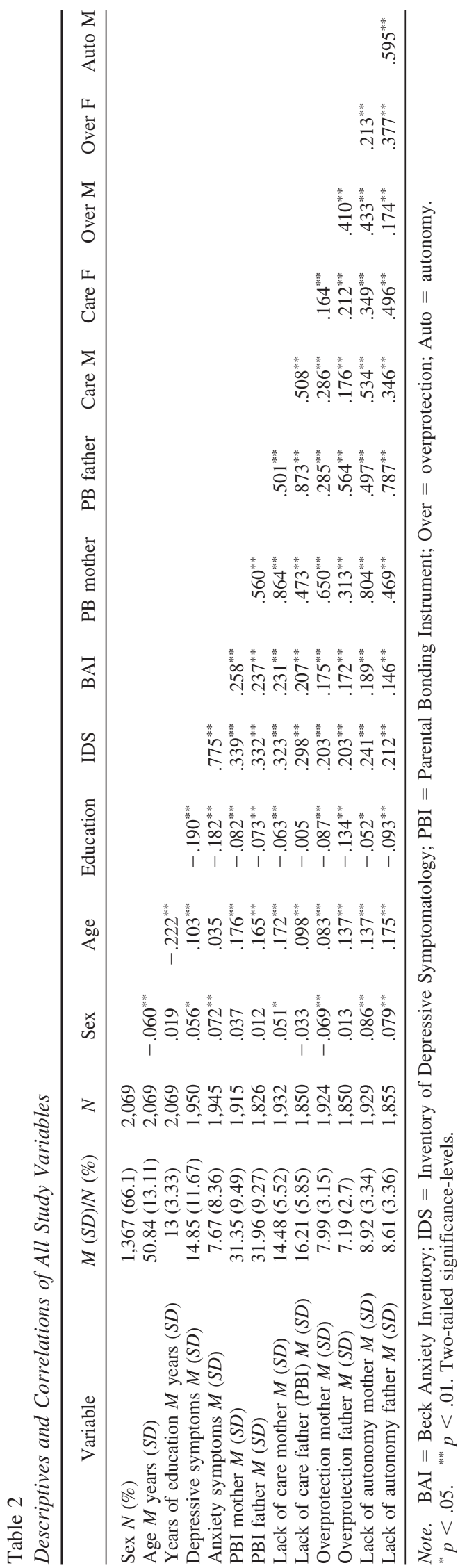

\section{Factor Structure and Measurement Invariance}

The first study aim was to evaluate the two versus three factor structure of the PBI in a clinical sample of lifetime depressed, anxious, comorbid affected, and healthy adults. Our results confirmed the three-factor structure representing Care, Overprotection, and Autonomy subscales, which is in line with the structure of the PBI proposed by Kendler et al. (1996) and with more recent studies in Western populations (Heider et al., 2005; Cox et al., 2000; Xu et al., 2018). It should be noted that the items reflecting negative parental behavior (e.g., "Tended to baby you" and "Seemed emotionally cold to me") show lower factor loadings on the care and overprotection dimensions compared with the items reflecting positive behavior (e.g., "Frequently smiled at you") as shown in Figure 1. Moreover, the low to moderate correlations between overprotection and lack of autonomy (Cohen, 1988) suggest that while the subscales are related, they reflect unique parental bonding styles. It should be noted, however, that, the Overprotection Scale mainly consists of negatively worded items whereas the Autonomy Scale contains positively worded items. It could, therefore, be thought that these two factors differ on methodological grounds, because items framed in the same direction tend to cluster. Nonetheless, the items of the Autonomy Scale refer to the extent in which parents encourage the child making own decisions, whereas the items of Overprotection Scale refer to the extent in which parents tend to baby and make the child dependent; therefore, it is assumed that also based on content subscales reflect distinct parental bonding dimensions. Further research into the convergent and discriminant validity of these subscales can help to understand the basis of these two subscales. Altogether, in western populations, we recommend using the three subscales as opposed to two subscales, particularly for the 16 -item version.

Using multiple group analysis, we evaluated measurement invariance of the three-factor model across sex and the four psychopathology groups as a configural model (equal factor structure), metric model (equal factor loadings), scalar model (equal factor loadings and equal intercepts), and strict model (plus equal residual variances). In line with the measurement invariance of a 24-item version of the PBI (Xu et al., 2018), we found evidence up to strict invariance across sex. Furthermore, our results show (scalar) invariance across depressed and anxious psychopathology groups for both paternal and maternal bonding examined with the abbreviated PBI version. Given the large sample size it can be concluded that the measurement of the PBI items is equal across sex or lifetime psychopathology diagnosis. The PBI can be reliably used to compare relations and latent means across sex and psychopathology groups.

\section{Males and Females and Parental Care, Overprotection, and Autonomy}

In our study, males reported higher levels of maternal overprotection and lack of care by their father compared with female participants. Females, on the other hand, reported the lack of care by their mothers more compared with males. Moreover, lack of autonomy levels were elevated in females compared with males, meaning that they perceive their parents as more restrictive than males do. In line with our findings, a large cohort study in a sample of American adolescents and adults has found that males report 
Table 3

Comparison of Psychopathology Groups on Clinical and Demographic Characteristics

\begin{tabular}{|c|c|c|c|c|c|c|c|}
\hline \multirow[b]{2}{*}{ Variable } & \multirow[b]{2}{*}{ Comorbid } & \multirow[b]{2}{*}{ Depression } & \multirow[b]{2}{*}{ Anxiety } & \multirow[b]{2}{*}{ Healthy } & \multicolumn{3}{|c|}{ Group comparison } \\
\hline & & & & & $d f$ & $F / \chi^{2}$ & Sig. \\
\hline Female sex $N(\%)$ & $795(69.4) \mathrm{a}$ & $211(64.3) a, b$ & $134(67.3) a, b$ & $227(57.3) \mathrm{b}$ & 3 & 19.7 & $<.001$ \\
\hline Age $M$ years $(S D)$ & $51.0(12.4) \mathrm{a}$ & $51.1(13.3) \mathrm{a}$ & $50.4(13.7) \mathrm{a}$ & $50.4(14.6) \mathrm{a}$ & 3 & 0.359 & 0.782 \\
\hline Years of education $M$ years $(S D)$ & $12.6(3.3) \mathrm{a}$ & $13.5(3.2) \mathrm{b}$ & $13.3(3.4) \mathrm{b}$ & $13.7(3.3) \mathrm{b}$ & 3 & 15.37 & $<.001$ \\
\hline Depressive symptoms $M(S D)$ & $19.9(12.3) \mathrm{a}$ & $11.2(8.1) \mathrm{b}$ & $10.3(6.9) \mathrm{b}$ & $6.0(5.1) \mathrm{c}$ & 3 & 212.1 & $<.001$ \\
\hline Anxiety symptoms $M(S D)$ & $10.9(9.3) \mathrm{a}$ & $4.5(4.9) \mathrm{b}$ & $5.7(6.0) \mathrm{b}$ & $2.4(3.4) \mathrm{c}$ & 3 & 149.5 & $<.001$ \\
\hline Current depressive disorder $N(\%)$ & $216(18.9) \mathrm{a}$ & $18(5.5) \mathrm{b}$ & $0(0) \mathrm{c}$ & $0(0) \mathrm{c}$ & 3 & 151.9 & $<.001$ \\
\hline Current anxiety disorder $N(\%)$ & 293 (25.6)a & $0(0) \mathrm{b}$ & $32(16.1) \mathrm{c}$ & $0(0) \mathrm{b}$ & 3 & 219.1 & $<.001$ \\
\hline
\end{tabular}

Note. Groups with the same letter ( $\mathrm{a}, \mathrm{b}$, or $\mathrm{c}$ ) did not differ significantly, groups with a different letter, differed from each other using Bonferroni post hoc testing $p<.05$.

less "affectionless-authoritarian" maternal bonding, that is, lack of autonomy, and more likely to report "neglectful/indifferent" paternal bonding, that is, lack of care, than females (de Cock \& Shevlin, 2014). Moreover, adolescent males reported to receive more permissive, that is, nonrestrictive, parenting and autonomy than females (McKinney \& Renk, 2008), which aligns our findings.

In view of a cohort growing up in the mid-20th century, the sex role theory (Bem, 1974) may account for the differences in reported lack of autonomy in our sample: Parents treated their sons and daughters differently, assuming that sons are more wired to take care of themselves and are more encouraged to be independent (Holmbeck, Paikoff, \& Brooks-Gunn, 1995). Also, in the context of particular masculine or feminine characteristics, males and females may perceive the role of their caregivers differently (Spence, 1993). However, we do not know to what extent this perception, as measured by the PBI, is reflecting a differential treatment of sons and daughters or rather reflect a mismatch in the needs of sons versus daughters in what they receive from their parents, regardless of whether parents treat their sons and daughters differently. Prospective and observational research are needed to elucidate whether these sex differences are mainly because of distinct parenting or rather explained by discrepancies in perception on the upbringing.

\section{Lack of Care, Overprotection, and Autonomy: Differences Across Psychopathology Groups}

In line with our hypothesis, lack of care, overprotection, and lack of autonomy were highest in comorbid affected (lifetime anxiety and depression) participants compared with lifetime depressed, lifetime anxious, and healthy participants. These results

Table 4

Measurement Invariance Across Sex and Across Psychopathology Groups for Maternal and Paternal Bonding

\begin{tabular}{|c|c|c|c|c|c|c|c|c|}
\hline Maternal bonding & $x^{2}$ & $d f$ & CFI & TLI & RMSEA & SRMR & $\Delta \mathrm{CFI}$ & Invariant? \\
\hline \multicolumn{9}{|l|}{ Across sex } \\
\hline Step 1: Configural invariance - Same factor structure & 1140.6 & 202 & 0.931 & 0.918 & 0.069 & 0.052 & & Yes \\
\hline Step 2: Metric invariance - Equal factor loadings & 1195.6 & 215 & 0.928 & 0.92 & 0.069 & 0.056 & 0.003 & Yes \\
\hline Step 3: Scalar invariance - Equal intercepts & 1281.0 & 228 & 0.923 & 0.919 & 0.069 & 0.058 & 0.005 & Yes \\
\hline Step 4: Strict invariance - Equal residual variance & 1323.3 & 244 & 0.921 & 0.922 & 0.067 & 0.058 & 0.002 & Yes \\
\hline \multicolumn{9}{|l|}{ Across psychopathology groups } \\
\hline Step 1: Configural invariance - Same factor structure & 1468.6 & 404 & 0.915 & 0.900 & 0.074 & 0.061 & & Yes \\
\hline Step 2: Metric invariance - Equal factor loadings & 1508.5 & 443 & 0.915 & 0.908 & 0.070 & 0.064 & 0.000 & Yes \\
\hline Step 3: Scalar invariance - Equal intercepts & 1573.9 & 482 & 0.913 & 0.914 & 0.068 & 0.066 & 0.002 & Yes \\
\hline Step 4: Strict invariance - Equal residual variance & 1948.3 & 530 & 0.887 & 0.898 & 0.074 & 0.073 & 0.026 & No \\
\hline Paternal bonding & $x^{2}$ & $d f$ & CFI & TLI & RMSEA & SRMR & $\Delta \mathrm{CFI}$ & Invariance? \\
\hline \multicolumn{9}{|l|}{ Across sex } \\
\hline Step 1: Configural invariance - Same factor structure & 1030.7 & 202 & 0.940 & 0.929 & 0.066 & 0.050 & & Yes \\
\hline Step 2: Metric invariance - Equal factor loadings & 1055.8 & 215 & 0.939 & 0.932 & 0.065 & 0.053 & 0.001 & Yes \\
\hline Step 3: Scalar invariance - Equal intercepts & 1175.1 & 228 & 0.932 & 0.928 & 0.067 & 0.055 & 0.007 & Yes \\
\hline Step 4: Strict invariance - Equal residual variance & 1216.4 & 244 & 0.930 & 0.931 & 0.065 & 0.055 & 0.002 & Yes \\
\hline \multicolumn{9}{|l|}{ Across psychopathology groups } \\
\hline Step 1: Configural invariance - Same factor structure & 1370.9 & 404 & 0.926 & 0.912 & 0.072 & 0.058 & & Yes \\
\hline Step 2: Metric invariance - Equal factor loadings & 1469.3 & 443 & 0.922 & 0.915 & 0.070 & 0.064 & 0.004 & Yes \\
\hline Step 3: Scalar invariance - Equal intercepts & 1547.7 & 482 & 0.919 & 0.919 & 0.069 & 0.065 & 0.003 & Yes \\
\hline Step 4: Strict invariance - Equal residual variance & 1913.4 & 530 & 0.895 & 0.905 & 0.075 & 0.073 & 0.024 & No \\
\hline
\end{tabular}

Note. $\mathrm{CFI}=$ comparative fit index $; \mathrm{CFI}=$ change in CFI; TLI $=$ Tucker-Lewis index; RMSEA $=$ root mean square error of approximation; SRMR $=$ standardized root mean square residual. Given our large sample and as $\chi^{2}$ is sensitive to sample size, we only used $\chi^{2}$ for descriptive purposes (Kline, 2010). 
Table 5

Latent Means Group Differences Between Males and Females

\begin{tabular}{|c|c|c|c|c|c|c|}
\hline \multirow[b]{2}{*}{ PBI subscale } & \multirow[b]{2}{*}{$\begin{array}{l}\text { Grand } M \\
{[95 \% \mathrm{CI}]}\end{array}$} & \multirow{2}{*}{ 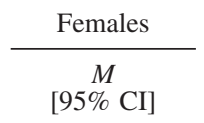 } & \multirow{2}{*}{$\frac{\text { Males }}{M}\left[\begin{array}{c}M \\
{[95 \% \mathrm{CI}]}\end{array}\right.$} & \multicolumn{3}{|c|}{ Group comparison } \\
\hline & & & & $\Delta \chi^{2}$ & $\Delta d f$ & $p$ \\
\hline Lack of care mother & $1.87[1.83,1.91]$ & $1.57[1.50,1.64]$ & $1.44[1.36,1.52]$ & 8.78 & 1 & $.003^{* *}$ \\
\hline Lack of care father & $2.03[1.98,2.07]$ & $1.63[1.56,1.71]$ & $1.79[1.71,1.88]$ & 11.76 & 1 & $<.001^{* * * *}$ \\
\hline Overprotection mother & $1.44[1.40,1.47]$ & $1.24[1.18,1.30]$ & $1.35[1.27,1.42]$ & 7.46 & 1 & $.006^{* * *}$ \\
\hline Overprotection father & $1.33[1.30,1.37]$ & $1.22[1.17,1.27]$ & $1.18[1.12,1.24]$ & 1.19 & 1 & .275 \\
\hline Lack of autonomy mother & $2.23[2.19,2.28]$ & $2.01[1.94,2.09]$ & $1.88[1.79,197]$ & 7.36 & 1 & $.007^{* * *}$ \\
\hline Lack of autonomy father & $2.20[2.16,2.25]$ & $2.02[1.94,2.10]$ & $1.86[1.77,1.95]$ & 10.72 & 1 & $.002^{* *}$ \\
\hline
\end{tabular}

Note. $\quad \mathrm{CI}=$ confidence interval. Reported test statistics are based on the overall comparison of the freely estimated vs. fully constrained models. Models comparing sexes are controlled for age, years of education, and current levels of anxiety and depression. PBI $=$ Parental Bonding Instrument.

*** $p<.01 .{ }^{* * * *} p<.001$.

corroborate findings of elevated levels of other risk factors (e.g., childhood trauma and neuroticism) in participants with comorbid depression and anxiety and reflect their additional susceptibility compared with individuals with a single diagnosis (Lamers et al., 2011). Personality characteristics, such as low self-esteem, introversion, emotional instability (Avagianou \& Zafiropoulou, 2008), and neuroticism (Enns, Cox, \& Larsen, 2000) are known to play a mediating role in the link between negative parental rearing and adult depression and anxiety. Therefore, elevated levels of neuroticism in the comorbid affected persons as described by Lamers and colleagues (2011) could partially explain the high levels of all suboptimal bonding types in this psychopathology group.

All three affected groups reported more lack of care by father and mother figures than the unaffected persons, which aligns with earlier findings (Burns et al., 2018; Kendler et al., 2000) and indicates the detrimental effect of relatively cold parenting in childhood on adult mental health. As with emotional neglect (Spinhoven et al., 2010), in particular, depression as compared with anxiety was related to higher paternal lack of care. Compared with the healthy controls, only comorbid affected patients reported heightened levels of overprotective parenting, whereas individuals who only developed either depression or anxiety did not report higher levels of overprotection. Those observations contrast with earlier studies showing that overprotected offspring is at an increased risk for both an anxiety and depressive disorder (Overbeek et al., 2007). Levels of lack of autonomy were elevated in all three affected groups compared with the unaffected persons. Generally, our findings contradict most of earlier findings that perceived authoritarian parenting is not related to adult depression and anxiety (e.g., Enns et al., 2002; Khalid et al., 2018). While some studies found that reported lack of autonomy have been shown to relate to increased adult psychopathology risk (Kendler et al., 2000; Seganfredo et al., 2009), others showed that, when controlling for the effects of care, associations between lack of autonomy and affective disorders were reduced (Gerlsma, Emmelkamp, \& Arrindell, 1990) or no longer significant (Kendler et al., 2000; Khalid et al., 2018).

However, in addition, our findings show some specific contrasts between depressive and anxiety-related psychopathology. When comparing depression and anxiety groups, adults with anxiety disorders reported higher levels of maternal lack of autonomy and adults with a depressive disorder reported higher levels of paternal lack of care. This indicates that individuals who perceive their mother as discouraging autonomy are specifically at risk to develop lifetime anxiety, whereas cold, affectionless parenting by father is specifically linked to adult depression. Maternal lack of care and paternal lack of autonomy had no specific link with anxiety or depression, but were elevated in both groups compared with healthy controls, meaning that persons reporting affectionless mothering or lack of encouragement and autonomy by father are at increased risk for both anxiety and depression. In addition to our analyses on the complete sample $(N=2,069)$, we ran analyses on lifetime psychopathology groups without participants with a current depression or anxiety diagnosis $(N=1,629)$ to isolate the effect of lifetime psychopathology (see Table S4 and S5 in the online supplemental materials). Results show that latent means were overall somewhat higher in the complete sample compared with the sample without current cases. However, out of the 24 tested group comparisons, three comparisons differed between the complete sample and the sample without current cases. More specifically, when removing cases with current depression or anxiety diagnoses, levels of paternal lack of care were equal across healthy and anxiety groups, levels of maternal lack of autonomy was equal across depression and anxiety groups and levels of paternal overprotection were now equal across the comorbid and depression groups. However, results from the sample without current cases may underestimate the levels of parental bonding in lifetime groups as the more chronically affected persons were removed from the analyses. Nevertheless, given the similar pattern of findings, it should be recognized that the presence and/or severity of current psychopathology may somewhat influence the magnitude of the association between parental bonding and lifetime psychopathology, although the influence seems to be small.

Suboptimal parental bonding reflects the retrospective perceptions of negative parent-offspring communication and unfavorable regulation of a child's behavior and is, therefore, conceptually closely linked to childhood emotional maltreatment by parents (Rikhye et al., 2008). Emotionally maltreating parental behavior consists of the active forms of abuse, such as insulting or given the feeling to be hated, and the passive neglecting forms, for instance lack of care when concern is needed or being indifferent to a child. The reported experiences of abusive or neglectful parenting is, therefore, intertwined with the recollections of the parental bond. Parental bonding problems and childhood emotional maltreatment, 
are the blueprint for negative internal working models and, therefore, contribute to maladaptive interpersonal schemas, deteriorated processing of social information and might result in dysfunctional relationships and insecure attachment as an adult (Bretherton et al., 1990; Riggs, 2010; Shapero et al., 2014) and consequently increase the risk for adult psychopathology (Blatt \& Homann, 1992; van Dam, Korver-Nieberg, Velthorst, Meijer, \& de Haan, 2014; Widom, Czaja, Kozakowski, \& Chauhan, 2018). In addition, dysfunctional emotion regulation is known to mediate suboptimal parenting and adult mood disorders. Parental emotional neglect and abuse increase negative cognitive processing (Ingram \& Ritter, 2000), rumination and behavioral avoidance, which are associated with depression (O'Mahen, Karl, Moberly, \& Fedock, 2015) and anxiety (Huh, Kim, Lee, \& Chae, 2017). Moreover, we found that emotionally maltreating parenting is also strongly linked with enhanced negative automatic (and explicit) self-associations, and increased depressive or anxious symptomatology (van Harmelen et al., 2010). Moreover, the association between inadequate care and psychopathology could be mediated by the increased exposure to adversities such as sexual abuse (McLaughlin et al., 2000), negative interaction with others (Meites et al., 2012) or increased likelihood of dysfunctional relationships (McCarthy \& Taylor, 1999) and could, therefore, make a person more vulnerable to anxiety or depression. Lastly, psychopathology in fathers or mothers could play a role in suboptimal parenting as well as adult psychopathology in offspring. In adult twins, it was found that genes accounted for $40 \%$ in the risk to depression (Kendler, Neale, Kessler, Heath, \& Eaves, 1992), whereas parenting explained only a small fraction in the liability to depression (Enns et al., 2002; Kendler et al., 2000). Parental anxiety was positively related to overinvolved parenting style, which was associated with stress and more anxiety adult offspring (Segrin, Woszidlo, Givertz, \& Montgomery, 2013). Therefore, an additional explanation of the association between suboptimal parental bonding and mood disorders could be the mediating role of parental psychopathology.

\section{Strengths, Limitations, and Future Directions}

Strengths of the current study are: the large sample including both lifetime affected and healthy persons. Psychopathology was carefully diagnosed and assessed across 9 years using the widely used CIDI interview (de Graaf et al., 2010; Kessler et al., 2010). Additionally, our study is (one of the) first comparing the suboptimal maternal and paternal bonding types between adult males and females and between people who are lifetime comorbid affected, depressed, anxious, and unaffected. Father and mother items differed in starting values indicating that measurement of the PBI was not invariant across father and mother scales. Also, based on the comparison across sexes and psychopathology groups, the patterns of associations were different for maternal versus paternal bonding. Therefore, we recommend to avoid aggregation of maternal and paternal scales in future research. Next to these strengths, some limitations need to be acknowledged. First, our sample may not represent an average community sample, as participants reported on average elevated levels of depression and anxiety symptoms, and moreover, consisted mainly of Dutch adults with moderate to high levels of education. Therefore, it is uncertain how findings generalize to more diverse populations and how parental bonding relates to externalizing psychopathology in 
$3.0-$

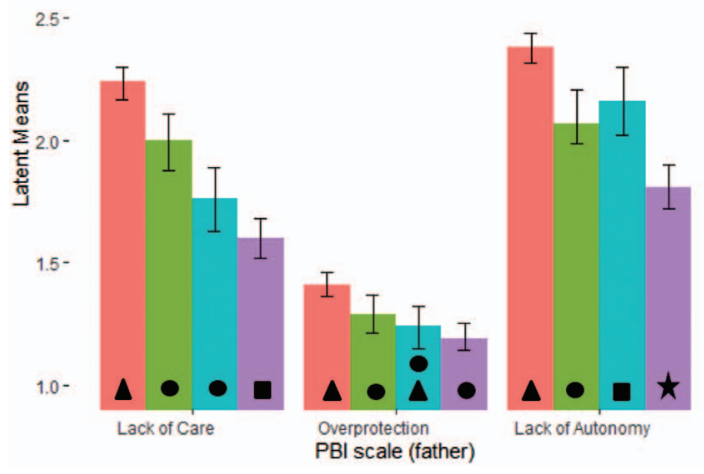

$3.0-$

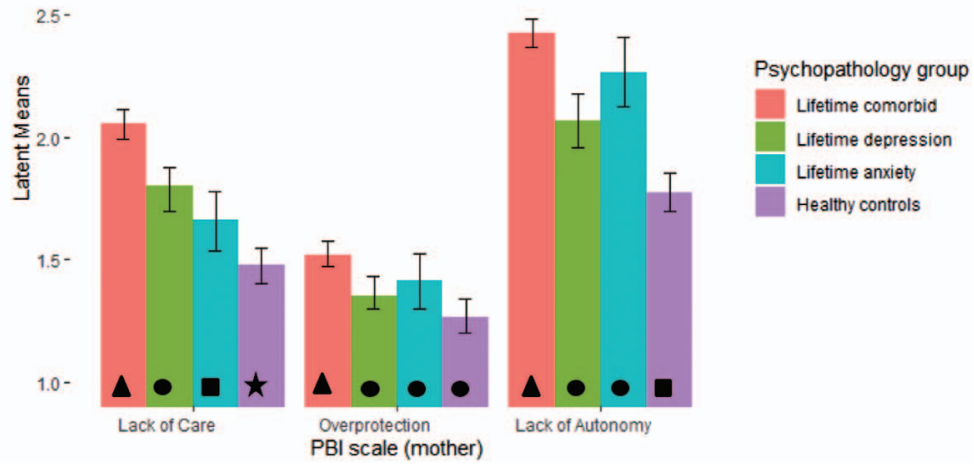

Figure 2. Latent mean differences in parental bonding between psychopathology groups $(N=2,069)$. Groups with the same symbol did not differ significantly on the Parental Bonding Instrument (PBI), groups with a different symbol, differed from each other. Significance level was corrected for multiple testing with BenjaminiHochberg procedure. See the online article for the color version of this figure.

adulthood (e.g., Lansford, Laird, Pettit, Bates, \& Dodge, 2014). Second, an alternative explanation for the elevated levels of suboptimal bonding in the comorbid affected participants is that a proportionally larger group also had current psychopathology, which could have influenced their reports on parental bonding. Earlier findings indicate that the perception of parenting is partially influenced by current mood and personality (Duggan, Sham, Minne, Lee, \& Murray, 1998; Reuben et al., 2016; Wilhelm, Niven, Parker, \& Hadzi-Pavlovic, 2005). However, previously it was found that the association of poor parental bonding during childhood remained a significant risk for developing a lifetime affective disorder after controlling for personality and current mood, even in late adulthood (Burns et al., 2018; Reuben et al., 2016). Moreover, studies show stability of reported parenting in childhood as measured by the PBI over a 20-years follow up into adulthood (Murphy, Wickramaratne, \& Weissman, 2010; Wilhelm et al., 2005). Lastly, our measurement invariance analyses have shown that the construct is measured in a same way when comparing affected versus unaffected participants. Third, directionality of the association could not be assessed because of the crosssectional design. One prospective study on the effects of early mother-child interaction showed that less maternal stimulation was associated with elevated depression risk in offspring in young adulthood (Schmid et al., 2011), whereas findings of a birth-tomaturity study in a Swedish cohort suggested that a suboptimal parent-child bond quality of partner relationship and life dissatisfaction, but not of depression or anxiety in midlife (Overbeek et al., 2007). Also, the developmental stage in which the detrimental parental behavior occurs, that is, timing, could be of crucial importance, which could not be investigated in our study, given the retrospective design and the fact that we did not inquire about parental binding during specific phases throughout childhood. Even though robust prospective and observational studies on overprotective and low supportive parenting of mothers and fathers in relation to child's internalizing psychopathology such as anxiety symptoms exists (e.g., Edwards, Rapee, \& Kennedy, 2010; Hastings et al., 2008; McShane \& Hastings, 2009; Pinquart, 2017), future studies with a longer prospective and/or multiple-informant design could corroborate the direction of the association between childhood parental bonding and (late) adult mood disorders and the impact of timing. Given the self-report nature of the PBI, it should be acknowledged that the construct reflects offspring's perceptions on childhood experiences. Concurrent (informant) reports on childhood experiences used in prospective studies and retrospective information show moderate agreement (Baldwin, Reuben, Newbury, \& Danese, 2019). Nevertheless, next to concurrent reports of childhood maltreatment, the adult perception of the past is linked to elevated psychopathology risk in adulthood (Newbury et al., 2018; Reuben et al., 2016). In the context of prospective research (e.g., Edwards et al., 2010; Hastings et al., 2008; McShane \& Hastings, 2009; Pinquart, 2017), findings on retrospective self-reports of parental bonding contribute to the literature in a way that negative perceptions of childhood parental bonding play an important role in psychopathology across the entire life span. Also, in clinical practice, current perceptions on childhood experiences rather than the occurrence of poor parenting in the past are used for diagnostic and intervention practices.

\section{Implications and Conclusion}

The present study confirmed the three-factor structure of the 16 item-version of the PBI, for example, lack of care, overprotection, and lack of autonomy (in previous studies often referred to as authoritarianism), and demonstrated that the PBI is measurement invariant across sex and psychopathology groups (depressed, anxious, comorbid, and healthy). This enabled us to compare reported parental bonding between males and females and between groups differing in terms of history of depression and/or anxiety patient. The measurement of the PBI was, however, not invariant across mother and father scales and the patterns of associations were differed across maternal and paternal bonding. Therefore, we dissuade aggregating mother and father scales in forthcoming studies. Altogether, our results suggest that the PBI is a reliable instrument to measure the perceived relationship with father and/or mother 
figures during childhood. Note that these conclusions are based on the 16-item version of the PBI and it is unclear whether results are applicable to other PBI versions such as the 25-item variant. Moreover, adults with a lifetime anxiety and/or depressive disorder perceive their childhood parental bonding less optimal as compared with healthy persons. Especially parental lack of care and lack of autonomy are associated with the presence of psychopathology later in life. These findings underline the importance of fostering positive and balanced parenting especially in children with signs of depression and/or anxiety to prevent (adult) psychopathology in offspring. Parents should be instructed about importance of parental warmth and autonomy and the negative long-term consequences of overprotectiveness for their offspring.

\section{References}

American Psychiatric Association. (2000). Diagnostic and statistical manual of mental disorders (4th ed., text rev.). Washington, DC: Author. http://dx.doi.org/10.1176/appi.books.9780890423349

Arbuckle, J. L. (1996). Full information estimation in the presence of incomplete data. In G. A. Marcoulides \& R. E. Schumacker (Eds.), Advanced structural equation modeling: Issues and techniques (pp. 243-277). Mahwah, NJ: Erlbaum.

Avagianou, P. A., \& Zafiropoulou, M. (2008). Parental bonding and depression: Personality as a mediating factor. International Journal of Adolescent Medicine and Health, 20, 261-269. http://dx.doi.org/10 .1515/IJAMH.2008.20.3.261

Baldwin, J. R., Reuben, A., Newbury, J. B., \& Danese, A. (2019, June 1). Agreement between prospective and retrospective measures of childhood maltreatment: A systematic review and meta-analysis. Journal of the American Medical Association Psychiatry, 76, 584-593. http://dx .doi.org/10.1001/jamapsychiatry.2019.0097

Bartholomew, K., \& Horowitz, L. M. (1991). Attachment styles among young adults: A test of a four-category model childhood attachment and internal models. Journal of Personality and Social Psychology, 61, 226-244. http://dx.doi.org/10.1037/0022-3514.61.2.226

Beck, A. T., Epstein, N., Brown, G., \& Steer, R. A. (1988). An inventory for measuring clinical anxiety: Psychometric properties. Journal of Consulting and Clinical Psychology, 56, 893-897.

Benjamini, Y., \& Hochberg, Y. (1995). Controlling the false discovery rate: A practical and powerful approach to multiple testing. Journal of the Royal Statistical Society: Series B (Methodological), 57, 289-300.

Bem, S. L. (1974). The measurement of psychological androgyny. Journal of Consulting and Clinical Psychology, 42, 155-162.

Blatt, S. J., \& Homann, E. (1992). Parent-child interaction in the etiology of dependent and self-critical depression. Clinical Psychology Review, 12, 47-91. http://dx.doi.org/10.1016/0272-7358(92)90091-L

Bowlby, J. (1997). Attachment and loss: Attachment (Vol. 1). New York, NY: Random House.

Bretherton, I., Ridgeway, D., \& Cassidy, J. (1990). Assessing internal working models of the attachment relationship: An attachment story completion task for 3-year-olds. In M. T. Greenberg, D. Cicchetti, \& E. M. Cummings (Eds.), The John D. and Catherine T. MacArthur Foundation series on mental health and development. Attachment in the preschool years: Theory, research, and intervention (pp. 273-308). Chicago, IL: University of Chicago Press.

Burbach, D. J., \& Borduin, C. M. (1986). Parent-child relations and the etiology of depression: A review of methods and findings. Clinical Psychology Review, 6, 133-153.

Buri, J. R. (1991). Parental authority questionnaire. Journal of Personality Assessment, 57, 110-119. http://dx.doi.org/10.1207/s15327752 jpa5701_13
Burns, R. A., Loh, V., Byles, J. E., \& Kendig, H. L. (2018). The impact of childhood parental quality on mental health outcomes in older adults. Aging \& Mental Health, 22, 819-825. http://dx.doi.org/10.1080/ 13607863.2017.1317331

Chen, F. F. (2007). Sensitivity of goodness of fit indexes to lack of measurement invariance. Structural Equation Modeling, 14, 464-504. http://dx.doi.org/10.1080/10705510701301834

Chen, F. F., Sousa, K. H., \& West, S. G. (2005). Teacher's corner: Testing measurement invariance of second-order factor models. Structural Equation Modeling, 12, 471-492. http://dx.doi.org/10.1207/s15 328007sem1203_7

Cheung, G. W., \& Rensvold, R. B. (2002). Evaluating goodness-of-fit indexes for testing measurement invariance. Structural Equation Modeling, 9, 233-255. http://dx.doi.org/10.1207/S15328007SEM0902_5

Cohen, J. (1988). Statistical power analysis for the behavioral sciences (2nd ed.). Hillsdale, NJ: Erlbaum.

Cox, B. J., Enns, M. W., \& Clara, I. P. (2000). The Parental Bonding Instrument: Confirmatory evidence for a three-factor model in a psychiatric clinical sample and in the National Comorbidity Survey. Social Psychiatry and Psychiatric Epidemiology, 35, 353-357. http://dx.doi .org/10.1007/s001270050250

de Cock, T. P., \& Shevlin, M. (2014). Parental bonding: A typology of the parent-child relationship in a population sample. SAGE Open, 4, 1-13. http://dx.doi.org/10.1177/2158244014547325

de Graaf, R., Radovanovic, M., van Laar, M., Fairman, B., Degenhardt, L., Aguilar-Gaxiola, S., . . A Anthony, J. C. (2010). Early cannabis use and estimated risk of later onset of depression spells: Epidemiologic evidence from the population-based World Health Organization World Mental Health Survey Initiative. American Journal of Epidemiology, 172, 149-159. http://dx.doi.org/10.1093/aje/kwq096

Duggan, C., Sham, P., Minne, C., Lee, A., \& Murray, R. (1998). Quality of parenting and vulnerability to depression: Results from a family study. Psychological Medicine, 28, 185-191. http://dx.doi.org/10.1017/ S0033291797006016

Edwards, S. L., Rapee, R. M., \& Kennedy, S. (2010). Prediction of anxiety symptoms in preschool-aged children: Examination of maternal and paternal perspectives. Journal of Child Psychology and Psychiatry, 51, 313-321. http://dx.doi.org/10.1111/j.1469-7610.2009.02160.x

Enns, M., Cox, B. J., \& Clara, I. (2002). Parental bonding and adult psychopathology: Results from the US National Comorbidity Survey. Psychological Medicine, 32, 997-1008.

Enns, M. W., Cox, B. J., \& Larsen, D. K. (2000). Perceptions of parental bonding and symptom severity in adults with depression: Mediation by personality dimensions. The Canadian Journal of Psychiatry, 45, 263 268.

Finzi-Dottan, R., \& Karu, T. (2006). From emotional abuse in childhood to psychopathology in adulthood: A path mediated by immature defense mechanisms and self-esteem. Journal of Nervous and Mental Disease, 194, 616-621. http://dx.doi.org/10.1097/01.nmd.0000230654.49933.23

Gerlsma, C., Emmelkamp, P. M. G., \& Arrindell, W. A. (1990). Anxiety, depression, and perception of early parenting: A meta-analysis. Clinical Psychology Review, 10, 251-277. http://dx.doi.org/10.1016/02727358(90)90062-F

Gregorich, S. E. (2006). Do self-report instruments allow meaningful comparisons across diverse population groups? Testing measurement invariance using the confirmatory factor analysis framework. Medical Care, 44(Suppl. 3), S78-S94. http://dx.doi.org/10.1097/01.mlr $.0000245454 .12228 .8 \mathrm{f}$

Hastings, P. D., Sullivan, C., McShane, K. E., Coplan, R. J., Utendale, W. T., \& Vyncke, J. D. (2008). Parental socialization, vagal regulation, and preschoolers' anxious difficulties: Direct mothers and moderated fathers. Child Development, 79, 45-64. http://dx.doi.org/10.1111/j .1467-8624.2007.01110.x 
Heider, D., Matschinger, H., Bernert, S., Alonso, J., \& Angermeyer, M. C., \& the ESEMeD/MHEDEA 2000 investigators. (2006). Relationship between parental bonding and mood disorder in six European countries. Psychiatry Research, 143, 89-98. http://dx.doi.org/10.1016/j.psychres .2005.08.015

Heider, D., Matschinger, H., Bernert, S., Vilagut, G., Martínez-Alonso, M., Dietrich, S., . . . the ESEMeD/MHEDEA 2000 Investigators. (2005). Empirical evidence for an invariant three-factor structure of the Parental Bonding Instrument in six European countries. Psychiatry Research, 135, 237-247. http://dx.doi.org/10.1016/j.psychres.2005.05.002

Holmbeck, G. N., Paikoff, R. L., \& Brooks-Gunn, J. (1995). Parenting adolescents. In M. H. Bornstein (Ed.), Handbook of parenting, Vol. 1. Children and parenting (pp. 91-118). Mahwah, NJ: Erlbaum.

Huh, H. J., Kim, K. H., Lee, H. K., \& Chae, J. H. (2017). The relationship between childhood trauma and the severity of adulthood depression and anxiety symptoms in a clinical sample: The mediating role of cognitive emotion regulation strategies. Journal of Affective Disorders, 213, 4450. http://dx.doi.org/10.1016/j.jad.2017.02.009

IBM Corp. (2017). IBM SPSS Statistics for Windows, Version 25.0. Armonk, NY: Author.

Ingram, R. E., \& Ritter, J. (2000). Vulnerability to depression: Cognitive reactivity and parental bonding in high-risk individuals. Journal of Abnormal Psychology Psychological Association, 109, 588-596. http:// dx.doi.org/10.1037/0021-843X.109.4.588

Kendler, K. S., Myers, J., \& Prescott, C. A. (2000). Parenting and adult mood, anxiety and substance use disorders in female twins: An epidemiological, multi-informant, retrospective study. Psychological Medicine, 30, 281-294. http://dx.doi.org/10.1017/S0033291799001889

Kendler, K. S., Neale, M. C., Kessler, R. C., Heath, A. C., \& Eaves, L. J. (1992). A population-based twin study of major depression in women. The impact of varying definitions of illness. Archives of General Psychiatry, 49, 257-266. http://dx.doi.org/10.1001/archpsyc.1992 .01820040009001

Kendler, K. S., Neale, M. C., Prescott, C. A., Kessler, R. C., Heath, A. C., Corey, L. A., \& Eaves, L. J. (1996). Childhood parental loss and alcoholism in women: A causal analysis using a twin-family design. Psychological Medicine, 26, 79-95. http://dx.doi.org/10.1017/ S0033291700033730

Kessler, R. C., McLaughlin, K. A., Green, J. G., Gruber, M. J., Sampson, N. A., Zaslavsky, A. M., . . . Williams, D. R. (2010). Childhood adversities and adult psychopathology in the WHO World Mental Health Surveys. The British Journal of Psychiatry, 197, 378-385. http://dx.doi .org/10.1192/bjp.bp.110.080499

Khalid, A., Qadir, F., Chan, S. W., \& Schwannauer, M. (2018). Parental bonding and adolescents' depressive and anxious symptoms in Pakistan. Journal of Affective Disorders, 228, 60-67.

Kitamura, T., Shikai, N., Uji, M., Hiramura, H., Tanaka, N., \& Shono, M. (2009). Intergenerational transmission of parenting style and personality: Direct influence or mediation? Journal of Child and Family Studies, 18, 541-556. http://dx.doi.org/10.1007/s10826-009-9256-z

Kline, R. B. (2010). Principles and practice of structural equation modeling (3rd ed.). New York, NY: Guilford Press.

Lamers, F., van Oppen, P., Comijs, H. C., Smit, J. H., Spinhoven, P., van Balkom, A. J. L. M., . . Penninx, B. W. J. H. (2011). Comorbidity patterns of anxiety and depressive disorders in a large cohort study: The Netherlands Study of Depression and Anxiety (NESDA). The Journal of Clinical Psychiatry, 72, 341-348. http://dx.doi.org/10.4088/JCP .10m06176blu

Lansford, J. E., Laird, R. D., Pettit, G. S., Bates, J. E., \& Dodge, K. A. (2014). Mothers' and fathers' autonomy-relevant parenting: Longitudinal links with adolescents' externalizing and internalizing behavior. Journal of Youth and Adolescence, 43, 1877-1889. http://dx.doi.org/10 .1007/s10964-013-0079-2
Lieb, R., Isensee, B., Höfler, M., Pfister, H., \& Wittchen, H.-U. (2002). Parental major depression and the risk of depression and other mental disorders in offspring: A prospective-longitudinal community study. Archives of General Psychiatry, 59, 365-374. http://dx.doi.org/10.1001/ archpsyc.59.4.365

Maciejewski, D. F., van Lier, P. A. C., Branje, S. J. T., Meeus, W. H. J., \& Koot, H. M. (2017). A daily diary study on adolescent emotional experiences: Measurement invariance and developmental trajectories. Psychological Assessment, 29, 35-49. http://dx.doi.org/10.1037/ pas0000312

Mackinnon, A. J., Henderson, A. S., Scott, R., \& Duncan-Jones, P. (1989). The Parental Bonding Instrument (PBI): An epidemiological study in a general population sample. Psychological Medicine, 19, 1023-1034. http://dx.doi.org/10.1017/S0033291700005754

Marsh, H. W., Hau, K.-T., \& Grayson, D. (2005). Goodness of fit in structural equation models. In A. Maydeu-Olivares \& J. J. McArdle (Eds.), Multivariate applications book series. Contemporary psychometrics: A festschrift for Roderick P. McDonald (pp. 275-340). Mahwah, NJ: Erlbaum Publishers.

Marshall, M., Shannon, C., Meenagh, C., Mc Corry, N., \& Mulholland, C. (2018). The association between childhood trauma, parental bonding and depressive symptoms and interpersonal functioning in depression and bipolar disorder. Irish Journal of Psychological Medicine, 35, 23-32.

McCarthy, G., \& Taylor, A. (1999). Avoidant/Ambivalent Attachment Style as a mediator between abusive childhood experiences and adult relationship difficulties. Journal of Child Psychology and Psychiatry, 40, 465-477. http://dx.doi.org/10.1111/1469-7610.00463

McKinney, C., \& Renk, K. (2008). Differential parenting between mothers and fathers: Implications for late adolescents. Journal of Family Issues, 29, 806-827. http://dx.doi.org/10.1177/0192513X07311222

McLaughlin, T. L., Heath, A. C., Bucholz, K. K., Madden, P. A. F., Bierut, L. J., Slutske, W. S., . . Martin, N. G. (2000). Childhood sexual abuse and pathogenic parenting in the childhood recollections of adult twin pairs. Psychological Medicine, 30, 1293-1302. http://dx.doi.org/10 .1017/S0033291799002809

McShane, K. E., \& Hastings, P. D. (2009). The new friends vignettes: Measuring parental psychological control that confers risk for anxious adjustment in preschoolers. International Journal of Behavioral Development, 33, 481-495. http://dx.doi.org/10.1177/0165025409103874

Meites, T. M., Ingram, R. E., \& Siegle, G. J. (2012). Unique and shared aspects of affective symptomatology: The role of parental bonding in depression and anxiety symptom profiles. Cognitive Therapy and Research, 36, 173-181.

Murphy, E., Wickramaratne, P., \& Weissman, M. (2010). The stability of parental bonding reports: A 20-year follow-up. Journal of Affective Disorders, 125, 307-315. http://dx.doi.org/10.1016/j.jad.2010.01.003

National Institute of Mental Health. (n.d.). Research Domain Criteria (RDoC) framework. Retrieved September 3, 2019, from https://www .nimh.nih.gov/research/research-funded-by-nimh/rdoc/units/self-reports/ 151519.shtml

Newbury, J. B., Arseneault, L., Moffitt, T. E., Caspi, A., Danese, A., Baldwin, J. R., \& Fisher, H. L. (2018). Measuring childhood maltreatment to predict early-adult psychopathology: Comparison of prospective informant-reports and retrospective self-reports. Journal of Psychiatric Research, 96, 57-64. http://dx.doi.org/10.1016/j.jpsychires.2017.09.020

Nordahl, H. M., \& Stiles, T. C. (1997). Perceptions of parental bonding in patients with various personality disorders, lifetime depressive disorders, and healthy controls. Journal of Personality Disorders, 11, 391-402.

Oakley-Browne, M. A., Joyce, P. R., Wells, J. E., Bushnell, J. A., \& Hornblow, A. R. (1995). Adverse parenting and other childhood experience as risk factors for depression in women aged 18-44 years. Journal of Affective Disorders, 34, 13-23. http://dx.doi.org/10.1016/ 0165-0327(94)00099-U 
O’Mahen, H. A., Karl, A., Moberly, N., \& Fedock, G. (2015). The association between childhood maltreatment and emotion regulation: Two different mechanisms contributing to depression? Journal of Affective Disorders, 174, 287-295. http://dx.doi.org/10.1016/j.jad.2014.11 .028

Overbeek, G., Stattin, H., Vermulst, A., Ha, T., \& Engels, R. C. M. E. (2007). Parent-child relationships, partner relationships, and emotional adjustment: A birth-to-maturity prospective study. Developmental Psychology, 43, 429-437. http://dx.doi.org/10.1037/0012-1649.43.2.429

Overbeek, G., ten Have, M., Vollebergh, W., \& de Graaf, R. (2007). Parental lack of care and overprotection. Longitudinal associations with DSM-III-R disorders. Social Psychiatry and Psychiatric Epidemiology, 42, 87-93. http://dx.doi.org/10.1007/s00127-006-0115-6

Parker, G., Tupling, H., \& Brown, L. B. (1979). A Parental Bonding Instrument. British Journal of Medical Psychology, 52, 1-10. http://dx doi.org/10.1111/j.2044-8341.1979.tb02487.x

Penninx, B. W. J. H., Beekman, A. T. F., Smit, J. H., Zitman, F. G., Nolen, W. A., Spinhoven, P., . . the NESDA Research Consortium. (2008). The Netherlands Study of Depression and Anxiety (NESDA): Rationale, objectives and methods. International Journal of Methods in Psychiatric Research, 17, 121-140. http://dx.doi.org/10.1002/mpr.256

Pinquart, M. (2017). Associations of parenting dimensions and styles with internalizing symptoms in children and adolescents: A meta-analysis. Marriage \& Family Review, 53, 613-640. http://dx.doi.org/10.1080/ 01494929.2016.1247761

Putnick, D. L., \& Bornstein, M. H. (2016). Measurement invariance conventions and reporting: The state of the art and future directions for psychological research. Developmental Review, 41, 71-90. http://dx.doi .org/10.1016/j.dr.2016.06.004

R Core Team. (2018). R: A language and environment for statistical computing. Vienna, Austria: R Foundation for Statistical Computing. Retrieved from https://www.R-project.org/

Reuben, A., Moffitt, T. E., Caspi, A., Belsky, D. W., Harrington, H., Schroeder, F., . . . Danese, A. (2016). Lest we forget: Comparing retrospective and prospective assessments of adverse childhood experiences in the prediction of adult health. Journal of Child Psychology and Psychiatry, 57, 1103-1112. http://dx.doi.org/10.1111/jcpp.12621

Riggs, S. A. (2010). Childhood emotional abuse and the attachment system across the life cycle: What theory and research tell us. Journal of Aggression, Maltreatment \& Trauma, 19, 5-51. http://dx.doi.org/10 $.1080 / 10926770903475968$

Rikhye, K., Tyrka, A. R., Kelly, M. M., Gagne, G. G., Jr., Mello, A. F., Mello, M. F., . . Carpenter, L. L. (2008). Interplay between childhood maltreatment, parental bonding, and gender effects: Impact on quality of life. Child Abuse \& Neglect, 32, 19-34. http://dx.doi.org/10.1016/j .chiabu.2007.04.012

Rosseel, Y. (2012). "lavaan: An R package for structural equation modeling." Journal of Statistical Software, 48, 1-36. Retrieved from http:// www.jstatsoft.org/v48/i02/

Rush, A. J., Giles, D. E., \& Schlesser, M. A. (1986). The inventory of depressive symptomatology (IDS): Preliminary findings. Psychopharmacology Bulletin, 22, 985-990. Retrieved from https://www .sciencedirect.com/science/article/pii/0165178186900600

Rush, A. J., Gullion, C. M., Basco, M. R., Jarrett, R. B., \& Trivedi, M. H. (1996). The Inventory of Depressive Symptomatology (IDS): Psychometric properties. Psychological Medicine, 26, 477-486. http://dx.doi .org/10.1017/s0033291700035558

Sato, T., Narita, T., Hirano, S., Kusunoki, K., Sakado, K., \& Uehara, T. (1999). Confirmatory factor analysis of the Parental Bonding Instrument in a Japanese population. Psychological Medicine, 29, 127-133.

Schmid, B., Blomeyer, D., Buchmann, A. F., Trautmann-Villalba, P., Zimmermann, U. S., Schmidt, M. H., . . Laucht, M. (2011). Quality of early mother-child interaction associated with depressive psychopathology in the offspring: A prospective study from infancy to adulthood.
Journal of Psychiatric Research, 45, 1387-1394. http://dx.doi.org/10 .1016/j.jpsychires.2011.05.010

Seganfredo, A. C. G., Torres, M., Salum, G. A., Blaya, C., Acosta, J., Eizirik, C., \& Manfro, G. G. (2009). Gender differences in the associations between childhood trauma and parental bonding in panic disorder. Revista Brasileira de Psiquiatria, 31, 314-321. http://dx.doi.org/10 .1590/S1516-44462009005000005

Segrin, C., Givertz, M., Swaitkowski, P., \& Montgomery, N. (2015). Overparenting is associated with child problems and a critical family environment. Journal of Child and Family Studies, 24, 470-479. http:// dx.doi.org/10.1007/s10826-013-9858-3

Segrin, C., Woszidlo, A., Givertz, M., \& Montgomery, N. (2013). Parent and child traits associated with overparenting. Journal of Social and Clinical Psychology, 32, 569-595. http://dx.doi.org/10.1521/jscp.2013 .32.6.569

Shapero, B. G., Black, S. K., Liu, R. T., Klugman, J., Bender, R. E., Abramson, L. Y., \& Alloy, L. B. (2014). Stressful life events and depression symptoms: The effect of childhood emotional abuse on stress reactivity. Journal of Clinical Psychology, 70, 209-223. http://dx.doi .org/10.1002/jclp.22011

Silove, D., Parker, G., Hadzi-Pavlovic, D., Manicavasagar, V., \& Blaszczynski, A. (1991). Parental representations of patients with panic disorder and generalised anxiety disorder. The British Journal of Psychiatry, 159, 835-841.

Spence, J. T. (1993). Gender-related traits, gender ideology: Evidence for a multifactorial theory. Journal of Personality-Social Psychology, 64, $624-635$.

Spinhoven, P., Elzinga, B. M., Hovens, J. G. F. M., Roelofs, K., Zitman, F. G., van Oppen, P., \& Penninx, B. W. J. H. (2010). The specificity of childhood adversities and negative life events across the life span to anxiety and depressive disorders. Journal of Affective Disorders, 126, 103-112. http://dx.doi.org/10.1016/j.jad.2010.02.132

Tsaousis, I., Mascha, K., \& Giovazolias, T. (2012). Can parental bonding be assessed in children? Factor structure and factorial invariance of the Parental Bonding Instrument (PBI) between adults and children. Child Psychiatry \& Human Development, 43, 238-253.

Valiente, C., Romero, N., Hervas, G., \& Espinosa, R. (2014). Evaluative beliefs as mediators of the relationship between parental bonding and symptoms of paranoia and depression. Psychiatry Research, 215, $75-81$.

van Dam, D. S., Korver-Nieberg, N., Velthorst, E., Meijer, C. J., \& de Haan, L., \& the For Genetic Risk and Outcome in Psychosis (GROUP) (2014). Childhood maltreatment, adult attachment and psychotic symptomatology: A study in patients, siblings and controls. Social Psychiatry and Psychiatric Epidemiology, 49, 1759-1767. http://dx.doi.org/10 .1007/s00127-014-0894-0

Vandenberg, R. J., \& Lance, C. E. (2000). A review and synthesis of the measurement invariance literature: Suggestions, practices, and recommendations for organizational research. Organizational Research Methods, 3, 4-70.

van Harmelen, A. L., de Jong, P. J., Glashouwer, K. A., Spinhoven, P., Penninx, B. W. J. H., \& Elzinga, B. M. (2010). Child abuse and negative explicit and automatic self-associations: The cognitive scars of emotional maltreatment. Behaviour Research and Therapy, 48, 486-494. http://dx.doi.org/10.1016/j.brat.2010.02.003

Wei, M., Heppner, P. P., \& Russell, D. W. (2006). Maladaptive perfectionism and ineffective coping as mediators between attachment and future depression: A prospective analysis. Article in Journal of Counseling Psychology, 53, 67-79. http://dx.doi.org/10.1037/0022-0167.53 .1 .67

Widom, C. S., Czaja, S. J., Kozakowski, S. S., \& Chauhan, P. (2018). Does adult attachment style mediate the relationship between childhood maltreatment and mental and physical health outcomes? Child 
Abuse \& Neglect, 76, 533-545. http://dx.doi.org/10.1016/j.chiabu .2017.05.002

Wilhelm, K., Niven, H., Parker, G., \& Hadzi-Pavlovic, D. (2005). The stability of the Parental Bonding Instrument over a 20-year period. Psychological Medicine, 35, 387-393. http://dx.doi.org/10.1017/ S0033291704003538

Wittchen, H. U. (1994). Reliability and validity studies of the WHOComposite International Diagnostic Interview (CIDI): A critical review. Journal of Psychiatric Research, 28, 57-84. http://dx.doi.org/10.1016/ 0022-3956(94)90036-1

Xu, M. K., Morin, A. J., Marsh, H. W., Richards, M., \& Jones, P. B. (2018). Psychometric validation of the parental bonding instrument in a
UK population-based sample: Role of gender and association with mental health in mid-late life. Assessment, 25, 716-728.

Yap, M. B. H., Pilkington, P. D., Ryan, S. M., \& Jorm, A. F. (2014). Parental factors associated with depression and anxiety in young people: A systematic review and meta-analysis. Journal of Affective Disorders, 156, 8-23. http://dx.doi.org/10.1016/j.jad.2013.11.007

Received November 8, 2019

Revision received April 22, 2020

Accepted April 23, 2020 